\title{
Excellent Agreement Between High Resolution EBSD and XRD Strain Measurements on $\mathrm{Si}_{1-x} \mathrm{Ge}_{x}$ films on $\mathrm{Si}$
}

\author{
M.D. Vaudin, W.A. Osborn, L.H. Friedman and R.F. Cook \\ Materials Measurement Science Division, National Institute of Standards and Technology, \\ Gaithersburg, MD 20899, USA
}

High resolution electron backscattered diffraction (HR-EBSD) is a rapidly evolving technique for measuring lattice strains and rotations with the potential for broad application in a number of areas, for example in microelectronics and microelectromechanical systems. The method measures strain differences between positions on a sample in a scanning electron microscope by cross correlating several equivalent regions in EBSD patterns obtained at those positions; the method has been described by Wilkinson et al. [1], and implemented in commercial software. This work describes ongoing efforts at NIST to establish an experimental basis for the accuracy of measured strains, and the spatial and strain resolutions of the technique. One primary goal of the work is to produce a Reference Material (RM) that contains strained and unstrained crystalline material in adjacent, coplanar regions of the artifact. To be useful, the regions must be at similar orientations $\left(\approx 1^{\circ}\right)$ and the strain must be known to an accuracy of $10^{-4}$. The artifacts chosen to fulfill these requirements consisted of $\mathrm{Si}_{1-x} \mathrm{Ge}_{x}$ films on $\mathrm{Si}$, with film thicknesses $(t)$ selected so that the films were epitaxial and electron diffraction occurred entirely in the film, and composition $(x)$ in the range 0.2 to 0.4 to produce coherency strains in the $1 \%$ to $2 \%$ range. The tetragonal strain, $\varepsilon_{t e t}$, in the film was defined:

$$
\varepsilon_{\text {tet }}=\varepsilon_{33}-\frac{\varepsilon_{11}+\varepsilon_{22}}{2}
$$

where the 1- and 2-axes are in the plane of the film and the 3-axis is normal to it.

Wafers of (001) Si with $\mathrm{Si}_{1-x} \mathrm{Ge}_{x}$ films of specific $x$ and $t$ values deposited on them were obtained from commercial semiconductor companies. Prototype devices were fabricated at NIST on $25 \mathrm{~mm}$ square dies with a number of features for various experiments, including stripes of $\mathrm{Si}_{1-x} \mathrm{Ge}_{x}$ with various widths and pitches for HR-EBSD measurements of strain, and a $20 \mathrm{~mm} \times 12.5 \mathrm{~mm}$ pad for $\mathrm{x}$-ray diffraction (XRD) measurements. XRD scans across the $\mathrm{Si} 004$ and $\mathrm{Si}_{1-x} \mathrm{Ge}_{x} 004$ peaks were taken, using equipment with a Johansson optic to suppress the X-ray beam $\mathrm{K} \alpha_{2}$ component, from which the $d$-spacings of the (004) planes of the film and substrate $\left(d_{\mathrm{Si004}}\right.$ and $\left.d_{\mathrm{SiGe004}}\right)$ were determined. The scan in Figure 1 from a film with nominal $x=0.3$ and $t=35 \mathrm{~nm}$ shows the $\mathrm{Si}$ and $\mathrm{Si}_{0.7} \mathrm{Ge}_{0.3} 004$ peaks and also residual $\mathrm{K \alpha}_{2}$ component on the right side of $\mathrm{Si} 004$. The $\mathrm{Si}_{1-x} \mathrm{Ge}_{x} 004$ peak has a number of oscillations on each side due to the perfection of the $\mathrm{Si}_{0.7} \mathrm{Ge}_{0.3}$ film and these oscillations were modeled to determine film thickness; this work is not presented here. Under the assumption that the film was epitaxial with the substrate so that the in-plane ((400) and (040)) $d$-spacings of $\mathrm{Si}_{0.7} \mathrm{Ge}_{0.3}$ and $\mathrm{Si}$ were the same, $\varepsilon_{\mathrm{xrd}}$ can be calculated as

$$
\varepsilon_{\mathrm{xrd}}=d_{\text {SiGe004}} / d_{\text {Si004 }}-1
$$

On the same sample, EBSD scans were made across several $50 \mu \mathrm{m}$ stripes of $\mathrm{Si}_{0.7} \mathrm{Ge}_{0.3}$, and Figure 2 shows the normal strains $\left(\varepsilon_{11}, \varepsilon_{22}, \varepsilon_{33}\right)$ generated from two $50 \mu \mathrm{m}$ stripes (marked A and B) using commercial software [2] to calculate the strains, followed by the use of eq. 1. The shaded regions indicate the data that were averaged to give the strains in the substrate (nominally zero) and film. These 
strains were subtracted to give the measurements in Table 1, which also contains the strain calculated from the XRD plot in Figure 1 using eq. 2. The agreement between the two EBSD measurements is good and their average agrees with the XRD result to within $3 \times 10^{-4}$. XRD is the more mature and tested technique and can easily yield results of high accuracy; $\pm 10^{-4}$ can be achieved on a routine basis. These results suggest that a RM of this type can be fabricated to validate the accuracy of EBSD strain measurements at the $\pm 3 \times 10^{-4}$ level, and potentially better.

References:

[1] A. Wilkinson, G. Meaden, D. Dingley, Ultramicroscopy 106 (2006), 307-313

[2] A. Wilkinson, G. Meaden, D. Dingley, Materials Science and Technology 22 (2006), 1271-1278

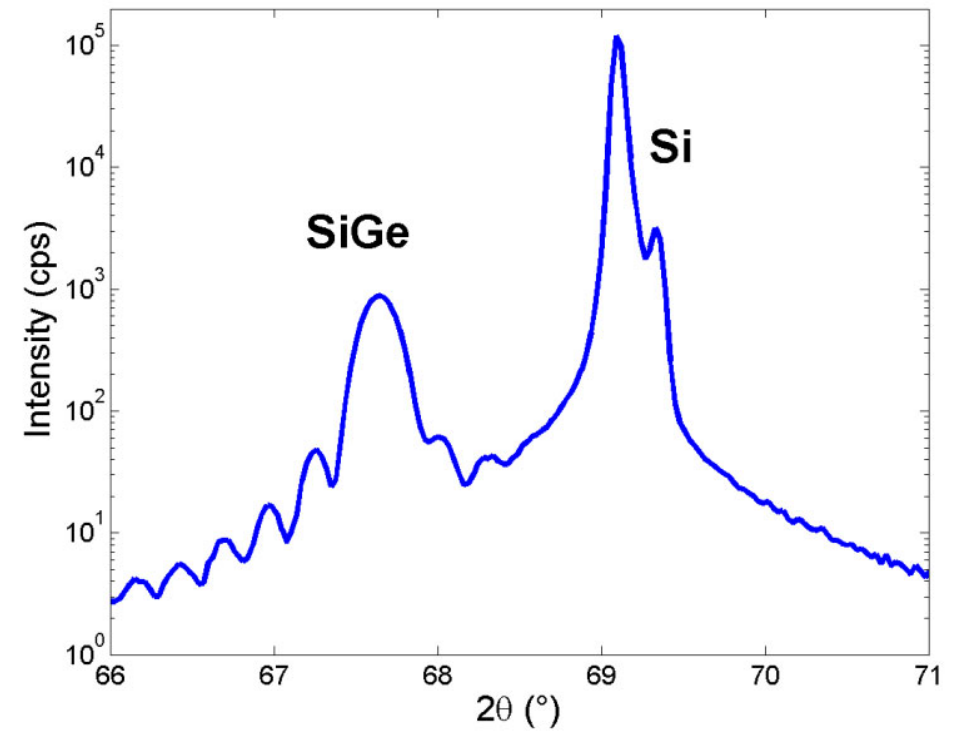

Figure 1. X-ray diffraction scan from $35 \mathrm{~nm} \mathrm{Si}_{0.7} \mathrm{Ge}_{0.3}$ on $\mathrm{Si}$

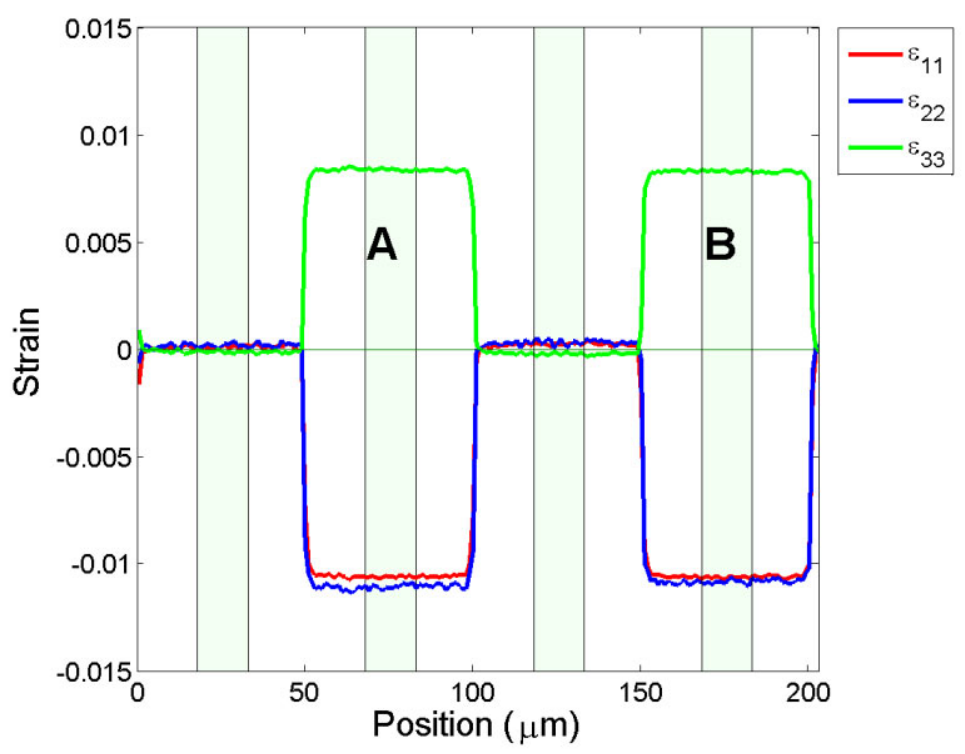

\begin{tabular}{|c|c|}
\hline Measurement & $\underline{\text { Strain }}$ \\
\hline XRD & 0.0189 \\
\hline EBSD A & 0.0187 \\
\hline EBSD B & 0.0185 \\
\hline
\end{tabular}

Table 1. EBSD and XRD results

Figure 2. EBSD data from $35 \mathrm{~nm} \mathrm{Si}_{0.7} \mathrm{Ge}_{0.3}$ on $\mathrm{Si}$ 